\title{
A NÃO VIOLAÇÃO DO DIREITO À INTIMIDADE NA FISCALIZAÇÃO DO E-MAIL CORPORATIVO POR PARTE DO EMPREGADOR: A configuração de justa causa pelo uso indevido do e-mail corporativo pelo empregado
}

\author{
Ana Gabriela Santos ${ }^{1}$ \\ Danielli Gadenz ${ }^{2}$ \\ Letícia Almeida de la Rue ${ }^{3}$ \\ Rossana Birck de Menezes ${ }^{4}$
}

\begin{abstract}
RESUMO: O presente artigo tem como escopo realizar sucinta análise acerca dos entraves judiciais decorrentes da fiscalização do e-mail corporativo do empregado pelo empregador em contraponto ao direito constitucional à intimidade e à privacidade, a partir de precedentes da Justiça do Trabalho. Justifica-se a relevância do tema, em razão da contínua e crescente problemática da violação destes direitos fundamentais pelos meios informáticos. Inclusive, decisões do TST ressaltam o ineditismo do problema em estudo. Trata-se, assim, de questão que envolve direitos fundamentais tutelados em nossa Constituição, e, portanto, não podem ser levianamente violados, devendo-se levar em conta, contudo, também a questão da proteção do empregador em face de atos inadequados do trabalhador no uso do email corporativo.
\end{abstract}

PALAVRAS-CHAVE: Direitos fundamentais. Privacidade. Intimidade. Monitoramento do E-mail Corporativo.

\section{THE NON-VIOLATION OF THE RIGHT TO PRIVACY WHEN IT COMES TO THE FISCALIZATION OF THE EMPLOYER'S EMAIL SYSTEM:}

The dismissal of employee for misuse of the employer's e-mail system

\begin{abstract}
This article performs a brief analysis of the legal hurdles on the employer's fiscalization of the email system in counterpoint to the employee's constitutional right to privacy based in the Labour Court cases. The Brazilian Supreme Labour Court reports the importance and novelty of the subject especially due the increasing problems caused by the violation of this fundamental right through the internet. Therefore, it is a constitutional fundamental right that cannot be violated as well as the issue of protecting the employer against the employee's inappropriate use of e-mail.

KEY-WORDS: Fundamental Rights. Monitoring Corporate E-mail.
\end{abstract}

\footnotetext{
$1 \quad$ Acadêmica do $8^{\circ}$ semestre do Curso de Direito da Universidade Federal da Santa Maria (UFSM). E-mail: anagabigs@ hotmail.com

2 Acadêmica do $8^{\circ}$ semestre do Curso de Direito da Universidade Federal da Santa Maria

(UFSM).E-mail: danigadenz@ hotmail.com

3 Acadêmica do $8^{\circ}$ semestre do Curso de Direito da Universidade Federal da Santa Maria

(UFSM). E-mail: Letícia_rue@yahoo.com

$4 \quad$ Acadêmica do $8^{\circ}$ semestre do Curso de Direito da Universidade Federal da Santa Maria

(UFSM). E-mail: rossanabirck@ hotmail.com
} 


\section{CONSIDERAÇÕES INICIAIS}

Com o advento da internet, as relações, não só as privadas, mas também as profissionais, estão utilizando cada vez mais as facilidades deste meio que aproxima as pessoas, dinamizando seus contatos e dando maior agilidade às suas tarefas. Como tudo que envolve relações humanas, as relações via Internet têm chegado também ao Poder Judiciário, esbarrando, principalmente, na falta de regulamentação legal específica.

No âmbito do Direito do Trabalho, a situação não é distinta. Os Tribunais têm sido acionados para se posicionarem sobre diversas questões relacionadas com a Internet, entre elas, as atinentes aos e-mails corporativos disponibilizados pelas empresas aos seus empregados. A questão é bastante polêmica, em especial no que tange ao uso desta ferramenta pelo funcionário e à existência de autorização legal do monitoramento do e-mail corporativo pelo empregador em contraponto ao direito à intimidade do trabalhador. No mesmo sentido, discute-se se o uso indevido desta ferramenta pode configurar justa causa para a rescisão do contrato de trabalho.

É essa problemática que dá ensejo ao presente trabalho, elaborado a partir do emprego do método dedutivo, pois a partir do estudo das linhas gerais a respeito do direito à intimidade, sinalizam-se os argumentos que fundamentam a justa causa na rescisão do contrato de trabalho. Os métodos de procedimento utilizados foram o científico, buscando estudar as alterações provocadas pelo uso de novas tecnologias no ambiente profissional, e o bibliográfico, através do qual restou possível a análise detalhada dos institutos que envolvem o tema da pesquisa, sob enfoque doutrinário.

Para melhor entendimento das premissas acima expostas, a abordagem do tema será dividida em três partes. Na primeira parte analisar-se-á o direito constitucional à intimidade e à privacidade, tecendo-se diferenciações e explicando qual melhor se coaduna aos casos em comento. Na segunda parte será feita a diferenciação entre o email pessoal e o e-mail corporativo, assim como os aspectos legais do monitoramento do e-mail corporativo pelo empregador. Por fim, tratar-se-á da maneira que o uso indevido do e-mail profissional pode configurar justa causa para a rescisão do contrato de trabalho.

\section{DIREITO À INTIMIDADE}


Para dar início ao presente estudo, cabe uma análise inicial acerca do conceito de intimidade e privacidade. José Afonso da Silva (1996, pg. 202) adota um conceito amplo de privacidade, entendendo que a privacidade é definida como "o conjunto da informação acerca do indivíduo, que ele pode decidir manter sob seu exclusivo controle, ou comunicar, decidindo a quem, quando, onde e em que condições".

Para Marcelo Cardoso Pereira (2003, pg. 117) “os conceitos de intimidade e de vida privada são indetermináveis, 'flutuantes' segundo o comportamento da pessoa e a influência de alguns aspectos externos. Não há como negar a existência de um vínculo entre vida privada e intimidade. Aquela abrange esta". Ambas, pertencentes à categoria dos direitos fundamentais, encontram respaldo na Constituição Brasileira.

Sônia Aguiar do Amaral Vieira (2002) entende a intimidade com a esfera mais reservada de uma pessoa, consistindo outrossim na prerrogativa do indivíduo excluir do conhecimento de terceiros aspectos de sua vida que não deseja ver expostos à publicidade alheia. Já a vida privada seria a esfera menos íntima do ser humano, tratando do direito de subtrair de terceiros fatos da vida particular. Têmis Limberger (2007) informa que o direito à intimidade tem por escopo defender o titular contra ataques não amparados por lei. Neste sentido, observa-se uma gradação entre o conceito de privacidade e intimidade, sendo esta última mais ligada ao espírito, dizendo respeito ao âmago do seu titular.

A aplicação da informática às relações pessoais, seja por parte do Estado ou de setores empresariais, no que tange ao tratamento das informações pessoais, passou a vulnerar o direito à intimidade dos usuários da Internet. Segundo Patrícia Peck Pinheiro (2009, pg. 42-43) "o Direito Digital tem o desafio de equilibrar a difícil relação existente entre interesse comercial, privacidade, responsabilidade e anonimato, gerada pelos novos veículos de comunicação".

Nas palavras de Marcelo Cardoso Pereira:

(...) os modernos computadores, com sua surpreendente capacidade de recolhimento (captura), armazenamento, tratamento e recuperação de informações, unidos à grande velocidade de transmissão de ditos dados por intermédio das distintas redes informáticas (incluída obviamente a Internet), representam um perigo a mais para a intimidade dos indivíduos. (PEREIRA, 2003, pg. 143) 
É nesta senda que violações a dados pessoais dos usuários da Internet podem constituir ataque a direitos fundamentais, constitucionalmente garantidos. Entretanto, cabe fazer uma ressalva. Haverá situações nas quais o interesse público irá se sobrepor ao privado, justificando, portanto, um sacrifício do direito à intimidade. Sônia Aguiar do Amaral Vieira pondera que (2002, pg. 28) "é imperioso que o interesse público a sobrepujar o particular, em termos de vida privada, seja indispensável, ou seja, só se justifica o sacrifício, na exata medida da necessidade e se o interesse superior não puder ser satisfeito por outra forma, seja ele de natureza pública ou privada”. Ou seja, somente nos casos específicos em que prevalece o interesse público é que pode haver restrição do direito à intimidade, sob pena de se ingressar no campo da ilicitude.

Deste modo, adentrando o campo do Direito do Trabalho, ao se analisar se a vigilância por parte do empregador em relação a informações pessoais do empregado especificamente, no uso do e-mail - trata-se de violação à intimidade, é preciso verificar se há um interesse maior que justifique tal comportamento.

\section{UTILIZAÇÃO DO E-MAIL NO AMBIENTE DE TRABALHO}

\subsection{E-Mail Pessoal e E-Mail Corporativo}

O Direito Eletrônico, considerado como um novo ramo do Direito, influencia os mais diversos institutos jurídicos, que buscam se adequar à nova realidade das relações sociais. Nesse sentido, o Direito do Trabalho e o Eletrônico estão cada vez mais interligados, uma vez que as inovações tecnológicas provocam mudanças nas relações humanas e, consequentemente, nas relações de emprego.

O advento da Internet se verificou a partir de necessidades militares, em 1969, pela Arpa - Advanced Research Projects Agency, setor de inteligência do Departamento de Defesa dos Estados Unidos da América. A Arpa tinha como objetivo propiciar a conexão entre diversos computadores, lotados em diferentes áreas, sem que houvesse um computador principal realizando a respectiva ligação (RUARO, 2007).

Essa tecnologia exclusivamente militar foi, com o tempo, aprimorada, transformando-se em uma ferramenta tecnológica indispensável à vida contemporânea. Com a evolução da Internet, novas ferramentas de aproximação virtual foram emergindo, como o eletronic mail (e-mail) que surgiu de uma experiência originada por 
Ray Tomlison, no ano de 1971, em Cambribge, Massachusetts. Através desse experimento, foi possível que diferentes usuários enviassem e recebessem mensagens, anexando documentos em vários formatos (texto, áudio, vídeo, etc.), em razão de um software instalado em um computador ligado a uma rede de telecomunicação, como telefone e cabo. (RUARO, 2007).

O uso dessa tecnologia, com o tempo, passou a ser empregada em larga escala nas mais diversas áreas de atuação e, conseqüentemente, alcançou também o ambiente de trabalho. Assim, a utilização de tais recursos tecnológicos traz diversas facilidades, uma vez que tal forma de comunicação possui baixo custo e é incrivelmente rápida, contribui para melhorar a eficiência e produtividade dos empregados, propiciando a comunicação com clientes, colegas de trabalho, além de transmissão de informações de modo mais eficiente e de refletir também na economia de papel e de outros materiais. Diante destas vantagens, as empresas estão cada vez mais lançando mão de tais recursos tecnológicos.

Deste modo, ao apreciar mais diretamente a questão do uso do e-mail no ambiente de trabalho, é importante ressaltar a diferença existente entre e-mail corporativo, objeto do presente trabalho, e e-mail particular. O primeiro é aquele que se constitui em ferramenta de trabalho, fornecido pelo empregador exclusivamente para a troca de mensagens que digam respeito ao interesse da empresa. Há, portanto, uma identificação direta com a empresa devido à adoção de nomenclatura do empregador, o chamado domínio na internet (exemplo: empregadofulano@empresatal.com.br). Já o email particular possui um caráter mais íntimo, sendo seu uso de responsabilidade e restrito a seu proprietário, é aquele provido por ente alheio ao empregador.

Assim, partindo-se da premissa de que o e-mail corporativo nada mais é que uma ferramenta de trabalho posta à disposição do empregado pelo empregador, por mera liberalidade deste, no tópico seguinte será analisada a possibilidade de o empregador monitorar o conteúdo veiculado nesta espécie de e-mail.

\subsection{Monitoramento do E-Mail Corporativo}

Após a conceituação e diferenciação entre e-mail pessoal e e-mail corporativo, cabe verificar se o monitoramento do e-mail pelo empregador encontra respaldo legal.

Nesta senda, Sérgio Pinto Martins entende que é plenamente possível que o empregador monitore o e-mail do empregado, dado que tal possibilidade decorre do 
poder de controle concedido ao empregador. Ressalta o autor (2009, pag. 199) que "não se pode dizer que haveria violação da privacidade do empregado quando o empregador exerce fiscalização sobre equipamentos de computador que lhe pertencem”. Continua ainda afirmando que (2009, pag. 199) “o correio eletrônico, em muitos casos, é da empresa e não do empregado (...) o empregador poderá verificar a utilização de emails, visando constatar se o computador não está sendo usado, no horário de serviço, para fins pessoais". Afinal, durante o horário de trabalho, o empregado está à disposição do empregador.

É neste sentido que se entende que, quando o empregador concede ao empregado e-mail da empresa, ou seja, e-mail corporativo, e lhe informa quais os usos que se espera desta ferramenta, cabe perfeitamente que monitore a destinação que está sendo dada pelo trabalhador. Isto ocorre porque, se o e-mail corporativo nada mais é que uma ferramenta de trabalho disponibilizada pelo empregador, nada mais justo que este controle se o seu uso não está sendo desviado

O uso indevido do e-mail corporativo, no dizer de Marcelo Oliveira Rocha (2004), acarreta a sobrecarga da memória e da rede utilizada internamente por toda a empresa. Ademais, há de ser levado em conta o inegável tempo de trabalho perdido pelo empregado para a leitura e envio de mensagens cujo interesse não se associa com o seu propósito laboral. É essa uma das questões justificativas da preocupação dos empregadores em monitorar esta ferramenta de trabalho.

Além da supracitada, outra hipótese de prejuízo a empresa, acarretada pelo uso indevido dos e-mails corporativos, é a propagação de mensagens com cunho discriminatório na Internet, posto que ao empregado enviar um e-mail com o logotipo da empresa ou até mesmo o fato de o endereço eletrônico remeter à empresa, está presente a possibilidade de o empregador ser identificado como corréu ou coobrigado em caso de indenização civil. Isto se dá porque a ferramenta eletrônica corporativa tratase, em verdade, de um documento oficial da empresa, até mesmo em virtude de que, em grande parte, o logotipo, a marca, ou timbre são anexos à mensagem enviada.

Dentro desta seara, diversas situações, como as acima citadas, são carecedoras de legislação própria, demandando um maior cuidado dos intérpretes e operadores das leis. O Poder Judiciário já vem enfrentando, nos últimos tempos, diversas questões envolvendo rescisões de contratos de trabalho decorrentes do uso indevido dos e-mails corporativos, configurando justa causa, como o envio de mensagens com fotos 
pornográficas ou a divulgação de mensagens obscenas, racistas, difamatórias, reveladoras de segredo empresarial, contendo vírus.

Portanto, observa-se assim que não viola o direito à intimidade do trabalhador o monitoramento do e-mail corporativo por parte do empregador, desde que o trabalhador seja previamente informado da possibilidade de ter seu correio eletrônico de uso profissional (e este é o uso esperado desta ferramenta de trabalho) fiscalizado pela empresa ou instituição. E isto se dá porque que há um motivo maior que autoriza tal vigilância, ou seja, a preocupação do empregador no sentido de que o empregado efetivamente exerça suas funções de maneira correta, não desvirtuando o uso do e-mail corporativo para um fim que não é de interesse da empresa.

Assim, corroborando o exposto, a regra de proteção à intimidade do empregado não pode ser entendida de forma absoluta, notadamente em face da má-fé no uso do email corporativo por parte do empregado. Quando houver motivo relevante, ou por política da instituição empregadora, mediante o prévio conhecimento de tal possibilidade pelo trabalhador, poderá, portanto, o empregador fiscalizar o e-mail corporativo sem que se configure controle vexatório (MARTINS, 2009).

\section{RESCISÃO DO CONTRATO DE TRABALHO}

\subsection{Justa Causa na Rescisão do Contrato de Trabalho}

A Consolidação das Leis do Trabalho, ao conceituar o empregado, informa que este presta serviços sob a dependência do empregador. Por sua vez, é o empregador, nos termos do art. $2^{\circ}$ da mesma legislação, quem dirige a prestação de serviços, pois assume os riscos da atividade econômica que explora. Assim, sendo o trabalhador o sujeito que suporta todos os riscos dos desacertos ou dos acertos resultantes de suas escolhas, lhe é concedida a possibilidade de intervir na relação de emprego, pois tem o poder de comando. Conforme preceitua Sérgio Pinto Martins (2009) tal prerrogativa decorre do poder de direção do empregador, que nada mais é que o modo como o empregador define como serão desenvolvidas as atividades do empregado decorrente do contrato de trabalho.

Desta forma, cabe ao empregador determinar as condições em que o trabalho deve se desenvolver, dirigindo a prestação de serviços, e ao empregado cabe apenas 
seguir as orientações dadas, utilizando para a execução de suas tarefas as ferramentas oferecidas pela empresa.

Consubstancia-se, assim, o direito do empregador de vigilância sobre o correto cumprimento dos afazeres de seus subordinados, que devem cumprir as instruções que lhes forem determinadas. Afinal, este é um espaço em que a privacidade do empregado cede perante o poder de direção do empregador, mesmo porque sobre este recai a responsabilidade civil pelos atos ilícitos praticados por aquele no exercício do trabalho ou em razão dele, nos termos do art. 932, III do Código Civil (GODINHO, 2011).

Neste sentido, uma vez verificado o procedimento incorreto por parte do empregado, tem o empregador o direito a desfazer o vínculo contratual, através da despedida por justa causa. A justa causa trata-se, pois, da conduta tipificada em lei que autoriza a resolução do contrato de trabalho por culpa do trabalhador. Destaca-se que a infração corresponde a um tipo legal preestabelecido, no entanto esse tipo legal nem sempre tem seus traços e contornos rigidamente fixados pela lei.

Desse modo, apesar de o Brasil ter adotado o sistema legislativo taxativo para motivar a resolução do contrato por justa causa, verifica-se significativa flexibilidade no ajuste do tipo legal, como, por exemplo, o disposto no art. 482, "b”, CLT, que autoriza a despedida por justa causa devido ao mau procedimento.

Cabe destacar que a dispensa por justa causa é a penalidade disciplinar máxima aplicada pelo empregador ao seu funcionário, quando este incorrer em falta grave que tornar desaconselhável o prosseguimento da relação de emprego, ferindo de morte fidúcia inerente à manutenção do ajuste.

Tal ato, por parte do empregador, é justificado ante a quebra da confiança, do liame subjetivo - e não somente objetivo - que une as partes envolvidas na relação jurídica, bastando que a falta grave ocorra uma única vez para que se desfaça o contrato de trabalho.

Destarte, dentre as hipóteses previstas na CLT, uma das faltas que implica em despedida por justa causa é o caso de improbidade por parte do empregado. Atente-se ao significado da palavra improbidade que, etimologicamente, indica maldade, malícia, perversidade, desonestidade. Assim, ímprobo é aquele que age de forma moralmente condenável e indevida, tal qual, conforme será explanado no tópico a seguir, o empregado que faz mau uso do e-mail corporativo, sendo-lhe, portanto, aplicável o conceito ora designado. 


\subsection{Fiscalização do E-Mail Corporativo como Configurador de Justa Causa na Rescisão do Contrato de Trabalho}

Nesse contexto, conforme já analisado, entende-se que o empregador tem direito a fiscalizar o e-mail corporativo do empregado, haja vista que se trata de ferramenta de trabalho e, portanto, não configura violação do direito fundamental à intimidade.

Contudo deve, para tanto, cientificar previamente o empregado, a fim de que este saiba que o e-mail corporativo poderá ser fiscalizado e, deste modo, evite veicular mensagens de cunho privado (para as quais existe o e-mail particular).

Assim, o empregado que utilizar o e-mail corporativo indevidamente para disseminar mensagens com teor ilícito - tais como as de conteúdo racista ou difamatório, por exemplo -, comete falta grave, ensejando punição por parte do empregador. Este poderá aplicar as penas permitidas por lei: advertência, suspensão e, inclusive, dispensa por justa causa. Percebe-se, portanto, que o procedimento incorreto do empregado, que utiliza correio eletrônico de forma indevida, enviando mensagens que podem até mesmo denegrir a imagem da empresa, configura ato de improbidade, e pode ensejar a rescisão contratual por justa causa.

No Brasil, tanto a doutrina quanto a jurisprudência têm autorizado o monitoramento do e-mail corporativo pelo empregador, tanto no tocante à finalidade efetivamente dada ao e-mail pelo empregado (envio de mensagens relacionadas à atividade da empresa), quanto ao conteúdo das mensagens. Assim, os Tribunais pátrios inclusive, já solidificaram entendimento no sentido de que, rompida a fidúcia pelo cometimento de falta grave, a inexistência de sanções anteriores não inibe a aplicação da penalidade.

A seguir, decisões do Tribunal Superior do Trabalho que corroboram a linha de pensamento sustentada:

AGRAVO DE INSTRUMENTO EM RECURSO DE REVISTA - E-MAIL CORPORATIVO - ACESSO PELO EMPREGADOR SEM A ANUENNCIA DO EMPREGADO - PROVA ILÍCITA NÃO CARACTERIZADA. Consoante entendimento consolidado neste Tribunal, o e-mail corporativo ostenta a natureza jurídica de ferramenta de trabalho, fornecida pelo empregador ao seu empregado, motivo pelo qual deve o obreiro utilizá-lo de maneira adequada, visando à obtenção da maior eficiência nos serviços que 
desempenha. Dessa forma, não viola os arts. $5^{\circ}$, X e XII, da Carta Magna a utilização, pelo empregador, do conteúdo do mencionado instrumento de trabalho, uma vez que cabe àquele que suporta os riscos da atividade produtiva zelar pelo correto uso dos meios que proporciona aos seus subordinados para o desempenho de suas funções. Não se há de cogitar, pois, em ofensa ao direito de intimidade do reclamante. (AIRR - 256281.2010.5.01.0000 Ministro Relator: Aloysio Corrêa da Veiga, $6^{a}$ Turma, Data de Publicação: DEJT 28/10/2010)

\section{PROVA ILÍCITA. "E-MAIL" CORPORATIVO. JUSTA CAUSA. DIVULGAÇÃO DE MATERIAL PORNOGRÁFICO.}

1. Os sacrossantos direitos do cidadão à privacidade e ao sigilo de correspondência, constitucionalmente assegurados, concernem à comunicação estritamente pessoal, ainda que virtual ("e-mail" particular). Assim, apenas o e-mail pessoal ou particular do empregado, socorrendo-se de provedor próprio, desfruta da proteção constitucional e legal de inviolabilidade.

2. Solução diversa impõe-se em se tratando do chamado "e-mail" corporativo, instrumento de comunicação virtual mediante o qual o empregado louva-se de terminal de computador e de provedor da empresa, bem assim do próprio endereço eletrônico que lhe é disponibilizado igualmente pela empresa. Destina-se este a que nele trafeguem mensagens de cunho estritamente profissional. Em princípio, é de uso corporativo, salvo consentimento do empregador. Ostenta, pois, natureza jurídica equivalente à de uma ferramenta de trabalho proporcionada pelo empregador ao empregado para a consecução do serviço.

3. A estreita e cada vez mais intensa vinculação que passou a existir, de uns tempos a esta parte, entre Internet elou correspondência eletrônica e justa causa elou crime exige muita parcimônia dos órgãos jurisdicionais na qualificação da ilicitude da prova referente ao desvio de finalidade na utilização dessa tecnologia, tomando-se em conta, inclusive, o princípio da proporcionalidade e, pois, os diversos valores jurídicos tutelados pela lei e pela Constituição Federal. A experiência subministrada ao magistrado pela observação do que ordinariamente acontece revela que, notadamente o " $e$ mail" corporativo, não raro sofre acentuado desvio de finalidade, mediante a utilização abusiva ou ilegal, de que é exemplo o envio de fotos pornográficas. Constitui, assim, em última análise, expediente pelo qual o empregado pode provocar expressivo prejuízo ao empregador.

4. Se se cuida de "e-mail" corporativo, declaradamente destinado somente para assuntos e matérias afetas ao serviço, o que está em jogo, antes de tudo, é o exercício do direito de propriedade do empregador sobre o computador capaz de acessar à INTERNET e sobre o próprio provedor. Insta ter presente também a responsabilidade do empregador, perante terceiros, pelos atos de seus empregados em serviço (Código Civil, art. 932, inc. III), bem como que está em xeque o direito à imagem do empregador, igualmente merecedor de tutela constitucional. Sobretudo, imperative considerar que o empregado, ao receber uma caixa de "e-mail" de seu empregador para uso corporativo, mediante ciência prévia de que nele somente podem transitar mensagens profissionais, não tem razoável expectativa de privacidade quanto a esta, como se vem entendendo no Direito Comparado (EUA e Reino Unido). 
5. Pode o empregador monitorar e rastrear a atividade do empregado no ambiente de trabalho, em "e-mail" corporativo, isto é, checar suas mensagens, tanto do ponto de vista formal quanto sob o ângulo material ou de conteúdo. Não é ilícita a prova assim obtida, visando a demonstrar justa causa para a despedida decorrente do envio de material pornográfico a colega de trabalho. Inexistência de afronta ao art. $5^{o}$, incisos X, XII e LVI, da Constituição Federal.

6. Agravo de Instrumento do Reclamante a que se nega provimento. (RR 613/2000-013-10-00, Ministro Relator: João Oreste Dalazen, Data de publicação: $10 / 6 / 2005)$

Em outra decisão análoga, o Ministro Aloysio Corrêa de Veiga, em julgamento da $6^{\text {a }}$ Turma do Tribunal Superior do Trabalho, proferido em 20 de outubro de 2010, ocasião em que relatou o processo, ressaltou não haver infração ao direito constitucional à intimidade, uma vez que o e-mail corporativo é ferramenta fornecida para o uso estritamente profissional, não possuindo o caráter pessoal do e-mail privado:

Não há afronta ao artigo $5^{\circ}$, incisos X e XII, da CF. O inciso X trata acerca da inviolabilidade da intimidade, da vida privada, da honra e da imagem das pessoas, $e$ o inciso XII, trata sobre o sigilo da correspondência e das comunicações de dados, o que no caso não se afigura, na medida em que retrata o caso em defesa acesso a sistema corporativo, que não guarda relação com informações pessoais, em email pessoal do empregado. (AIRR - 256281.2010.5.01.0000, Ministro relator: Aloysio Corrêa de Veiga, $\sigma^{a}$ turma, data da publicação 20/10/2010). [grifo nosso]

Neste sentido, já decidiu também o Tribunal Regional do Trabalho da $4^{a}$ Região:

Despedida por justa causa. Mau procedimento. Uso indevido de correio eletrônico. Quando se caracteriza. Prova que evidencia a utilização do email funcional, pelo empregado, para difundir informações tendentes a denegrir a imagem da empregadora. Constitui justa causa para a despedida o uso indevido do correio eletrônico fornecido pelo empregador, não se podendo cogitar de infração ao disposto no artigo $5^{\circ}$, inciso XII da CF, já que o serviço de "e-mail" é ferramenta fornecida para uso estritamente profissional. Sentença mantida. (Relator: FLAVIO PORTINHO SIRANGELO. Origem: $3^{a}$ Vara do Trabalho de Canoas. Acórdão - Processo 0016800-02.2007.5.04.0203. RO. Data: 03/09/2008).

JUSTA CAUSA. ATO DE IMPROBIDADE. Hipótese em que a ex-empregada enviava e-mails a colegas de trabalho manifestando sua intenção de forçar a empresa a demiti-la, cujo rastreamento dos conteúdos respectivos era do seu conhecimento. (Origem: $8^{a}$ Vara do Trabalho de Porto Alegre. Relator: EMÍLIO PAPALÉO ZIN. Acórdão - Processo 0110200-05.2009.5.04. 0008. RO. Data: 07/04/2011). 
Da mesma forma, perfilando-se ao entendimento exarado alhures, os Tribunais Regionais do Trabalho da $16^{\mathrm{a}}$ Região e $2^{\mathrm{a}}$ Região, respectivamente:

DEMISSÃO POR JUSTA CAUSA. CABIMENTO. ART. 482, b e h.É legítima a despedida por justa causa, nos termos do artigo 482, alíneas $b$ e $h$ da CLT, uma vez que ficou devidamente provada a conduta indisciplinada $e$ incontinente do empregado, quando, descumprindo orientações expressas do empregador as quais tinha ciência, enviava e recebia correspondências eletrônicas de cunho pornográfico através do provedor do empregador e por meio de seu e-mail corporativo, ocasionando, assim, a quebra de fidúcia justificadora da resilição contratual. Recurso ordinário conhecido e improvido. 482CLT. (1226200701616000 MA 01226-2007-016-16-00-0, Relator: AMÉRICO BEDÊ FREIRE, Data de Jugamento: 28/09/2010, Data de Publicação: 04/10/2010)

Correio eletrônico. Monitoramento. Legalidade. Não fere norma constitucional a quebra de sigilo de e-mail corporativo, sobretudo quando o empregador dá a seus empregados ciência prévia das normas de utilização do sistema e da possibilidade de rastreamento e monitoramento de seu correio eletrônico. (RO 1130200404702004 SP 01130-2004-047-02-00-4, Relator: WILSON FERNANDES, Data de Jugamento: 09/11/2006, $1^{a}$ TURMA, Data de Publicação: 28/11/2006)

Observa-se, por fim, que não se pode confundir o e-mail corporativo, que pertence à empresa, como e-mail particular, de domínio pessoal do empregado. Com base nessa diferença crucial não se pode admitir a sondagem por parte do empregador daquilo que é veiculado nas mensagens enviadas por e-mail particular, ainda que encaminhadas a partir dos computadores da empresa, visto que configuraria violação ao direito à privacidade.

É por isto que as mensagens particulares veiculadas no e-mail corporativo por liberalidade do empregado, ou seja, nos casos em que o empregado disponibiliza o email corporativo para fins pessoais, podem ser monitoradas, pois se afigura inviável que a empresa distinga o caráter das mensagens recebidas em tal e-mail. Além disto, o email corporativo ostenta natureza jurídica equivalente a de uma ferramenta de trabalho proporcionada pelo empregado ao empregador para a consecução do serviço, podendo o empregado checar suas mensagens tanto do ponto de vista formal quanto sob o ângulo material ou de conteúdo.

Neste sentido corrobora a jurisprudência do Tribunal Superior do Trabalho: 
RECURSO DE REVISTA OBREIRO: DANO MORAL - NÃO CARACTERIZAÇÃO - ACESSO DO EMPREGADOR A CORREIO ELETRONNICO CORPORATIVO - LIMITE DA GARANTIA DO ART. 5\%, XII, $D A C F$.

1. O art. $5^{\circ}, X I I$, da CF garante, entre outras, a inviolabilidade do sigilo da correspondência e da comunicação de dados.

2. A natureza da correspondência e da comunicação de dados é elemento que matiza e limita a garantia constitucional, em face da finalidade da norma: preservar o sigilo da correspondência - manuscrita, impressa ou eletrônica da pessoa - física ou jurídica - diante de terceiros.

3. Ora, se o meio de comunicação é o institucional - da pessoa jurídica -, não há de se falar em violação do sigilo de correspondência, seja impressa ou eletrônica, pela própria empresa, uma vez que, em princípio, o conteúdo deve ou pode ser conhecido por ela.

4. Assim, se o "e-mail" é fornecido pela empresa, como instrumento de trabalho, não há impedimento a que a empresa a ele tenha acesso, para verificar se está sendo utilizado adequadamente. Em geral, se o uso, ainda que para fins particulares, não extrapola os limites da moral $e$ da razoabilidade, o normal será que não haja investigação sobre o conteúdo de correspondência particular em "e-mail" corporativo. Se o trabalhador quiser sigilo garantido, nada mais fácil do que criar seu endereço eletrônico pessoal, de forma gratuita, como se dá com o sistema "gmail" do Google, de acesso universal.

5. Portanto, não há dano moral a ser indenizado, em se tratando de verificação, por parte da empresa, do conteúdo do correio eletrônico do empregado, quando corporativo, havendo suspeita de divulgação de material pornográfico, como no caso dos autos.

(Processo: ED-RR - 996100-34.2004.5.09.0015 Data de Julgamento: 18/02/2009, Relator Ministro: Ives Gandra Martins Filho, $7^{a}$ Turma, Data de Publicação: DEJT 20/02/2009).(grifos)

Assim, cabe ao empregado não fazer uso do e-mail corporativo para fins pessoais. De maneira complementar, se o empregador pretende evitar o uso das máquinas da empresa para fins pessoais, este pode vedar o acesso a certas páginas da internet, pois há meios técnicos para tanto.

\section{CONSIDERAÇÕES FINAIS}

Considerando-se o e-mail corporativo como uma ferramenta de trabalho posta à disposição do empregado pelo empregador, entende-se plenamente viável que este fiscalize a destinação que está sendo dada ao e-mail, sem que este procedimento revele afronta ao direito constitucional à intimidade.

A fiscalização não é dependente da utilização dada pelo empregado ao e-mail corporativo. Assim, não toca ao empregado alegar uso pessoal e não ilícito do e-mail 
oferecido pela entidade empregadora, uma vez que este é ferramenta posta à sua disposição única e exclusivamente para a realização do trabalho, sendo, portanto, de propriedade da empresa, e, tal como em relação à qualquer tarefa executada no exercício das atividades de seus empregados, é direito da instituição realizar a fiscalização.

Afinal, a empresa pode vir a ser prejudicada, e até mesmo responsabilizada criminal e civilmente, pelo mau procedimento do empregado, tanto no uso do e-mail, por exemplo, através da divulgação de mensagens discriminatórias, difamatórias, reveladoras de segredo empresarial, entre tantas outras possibilidades, quanto de qualquer outro instrumento de trabalho.

Deste modo, constatando-se mau procedimento no uso do e-mail corporativo, quebra-se a confiança esperada no vínculo da relação de emprego, tornando viável até mesmo a rescisão do contrato de trabalho por justa causa.

\section{REFERÊNCIAS BIBLIOGRÁFICAS}

ATHENIENSE, Alexandre. O monitoramento eletrônico e as relações trabalhistas. Âmbito Jurídico, Rio Grande, 46, 31 de outubro de 2007. Disponível em: $<$ http://www.ambitojuridico.com.br/site/index.php?n_link=revista_artigos_leitura\&artig o_id=2382>. Acesso em 28/05/2011.

BARROS, Alice Monteiro de. Curso de Direito do Trabalho. Rio de Janeiro: Renovar, 2002.

BRASIL. Tribunal Superior do Trabalho. Agravo de instrumento em recurso de revista e-mail corporativo - acesso pelo empregador sem a anuência do empregado - prova ilícita não caracterizada. AIRR - 2562-81.2010.5.01.0000. Ministro relator: Aloysio Corrêa da Veiga, $6^{a}$ turma, data de publicação: 28/10/2010. Disponível em: http://ext02.tst.jus.br/pls/ap01/ap_red100.resumo?num_int=116554\&ano_int=2010\&qtd _acesso=2812287. Acesso em: Junho/2011

Tribunal Superior do Trabalho. Prova ilícita. "e-mail" corporativo. Justa causa. Divulgação de material pornográfico. Agravo de Instrumento RR - 613/2000-013-1000. HSBC Seguros Brasil S.A E Elielson Lourenço do Nascimento. Ministro Relator: João Oreste Dalazen. Data de publicação: 10/6/2005. Disponível em: http://ext02.tst.jus.br/pls/ap01/ap_red100.resumo?num_int=29569\&ano_int=2003\&qtd_ acesso $=1510065$. Acesso em: Junho/2011

Tribunal Superior do Trabalho. ED-RR - 996100-34.2004.5.09.0015 Data de Julgamento: 18/02/2009, Relator Ministro: Ives Gandra Martins Filho, $7^{\text {a }}$ Turma, Data de Publicação: DEJT 20/02/2009. OTTO RHEINSCHMITT e ESSO BRASILEIRA DE 
PETRÓLEO LTDA. Disponível em: http://aplicacao5.tst.jus.br/consultaunificada2/ jurisSearchInSession.do?action $=$ search $\&$ basename $=$ acordao\&index $=20$. Acesso em: Dezembro/2011

CANOTILHO, José Joaquim Gomes. Direito Constitucional e Teoria da Constituição. 3 ed. Almedina: Coimbra, 1999.

DELGADO, Mauricio Godinho. Curso de direito do trabalho. 8 ed. São Paulo: LTr, 2009.

GODINHO, Adriano Marteleto. E-mail corporativo e direito à privacidade. Disponível em: <http:juristas.com.br/informação/revista-juristas/e-mail-corporativo-edireito-a-privacidade/13/print/>. Acesso em: maio/2011.

KELSEN, Hans. Jurisdição constitucional. São Paulo: Martins Fontes, 2003

LIMBERGER, Têmis. O Direito à Intimidade na Era da Informática. Porto Alegre: Livraria do Advogado, 2007.

MACEDO, Rafhael Duarte. O E-mail corporativo. Universo Jurídico, 01 de abril de 2009. Disponível em: 〈http://www.uj.com.br/publicacoes/doutrinas/6160/O_E-mail_Corporativo〉. Acesso em: 28 de maio 2011.

MARANHÃO. Tribunal Regional do Trabalho da 16 ${ }^{\mathrm{a}}$ Região. Recurso Ordinário Demissão Por Justa Causa. 482clt. Elton De Jesus Pereira E Alcoa Alumínio S.A. \& Billiton Metais S.A. Processo n. 1226200701616000 MA 01226-2007-016-16-00-0, Relator: Américo Bedê Freire. Data de Jugamento: 28/09/2010. Data de Publicação: 04/10/2010. Disponível em: http://www.trt16.gov.br/site/index.php?acao=conteudo/ processo/processo2.php\&seq_processo=79846. Acesso em: Junho/2011

MARRANHÃO, Délio; CARVALHO, Luiz Inácio Barbosa. Direito do Trabalho. 17 ed. Rio de Janeiro: Editora da FGV, 1993.

MARTINS, Sérgio Pinto. Direito do Trabalho. São Paulo: Editora Atlas, 2009.

MORAES, Alexandre de. Direito Constitucional. 19ª edição. São Paulo: Atlas, 2006.

PEREIRA, Marcelo Cardoso. Direito à Intimidade na Internet. Curitiba: Juruá Editora, 2003.

PINHEIRO, Patrícia Peck. Direito Digital. São Paulo: Saraiva, 2009.

RIO GRANDE DO SUL. Tribunal Regional do Trabalho. Recurso Ordinário. Despedida por justa causa. Mau procedimento. Uso indevido de correio eletrônico. Ângelo Luís Roveda E Comunidade Evangélica Luterana São Paulo CELSP. Processo0016800-02.2007.5.04.0203. RO. Data: 03/09/2008. Relator: Flavio Portinho Sirangelo. Origem: $3^{\mathrm{a}}$ Vara do Trabalho de Canoas. Disponível em: http://www.trt4.jus.br/portal/portal/trt4/consultas/consulta_rapida/ConsultaProcessualW indow?svc=consultaBean\&nroprocesso $=0016800-02.2007 .5 .04 .0203 . \quad$ Acesso em: Junho/2011. 
RIO GRANDE DO SUL. Tribunal Regional do Trabalho. Recurso Ordinário. Justa Causa. Ato de Improbidade. Zayama Oliveira Meneses E Banco Topázio S.A.. Processo 0110200-05.2009.5.04. 0008. RO. Data: 07/04/2011. Origem: $8^{a}$ Vara do Trabalho de Porto Alegre. Relator: Emílio Papaléo Zin. Data: 07/04/2011. Disponível em: http://www.trt4.jus.br/portal/portal/trt4/consultas/consulta_rapida/ConsultaProcessualW indow $? \mathrm{svc}=$ consultaBean $\&$ action $=\mathrm{e} \&$ windowstate $=$ normal $\&$ mode $=$ view. Acesso em: Julho/2011.

SÃO PAULO. Tribunal Regional do Trablho $2^{\mathrm{a}}$ Região. Recurso Ordinário. Correio eletrônico. Monitoramento. Legalidade. Roberto Bicineri Pereira E Nestle Brasil Ltda. RO 1130200404702004 SP 01130-2004-047-02-00-4, Relator: Wilson Fernandes. Data de Jugamento: 09/11/2006, 1ª TURMA, Data de Publicação: 28/11/2006. Disponível em: http://trt.trtsp.jus.br/dwp/consultasphp/public/index.php/primeiraInstancia/andamen to/processo/01130001620045020047. Acesso em: Junho/ 2011.

SILVA, José Afonso da. Curso de Direito Constitucional Positivo. São Paulo: Malheiros Editores, 2002.

VIEIRA, Sônia Aguiar do Amaral. Inviolabilidade da vida privada e da intimidade pelos meios eletrônicos. São Paulo: Editora Juarez de Oliveira, 2002. 